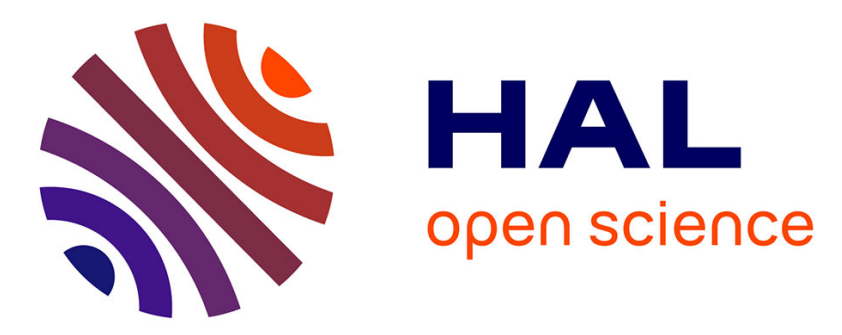

\title{
Contribution of electrochemical dissolution during pickling of low carbon steel in acidic solutions
}

Amine Alaoui Mouayd, Mark E. Orazem, Eliane Sutter, Bernard Tribollet, A. Koltsov

\section{- To cite this version:}

Amine Alaoui Mouayd, Mark E. Orazem, Eliane Sutter, Bernard Tribollet, A. Koltsov. Contribution of electrochemical dissolution during pickling of low carbon steel in acidic solutions. Corrosion Science, 2014, 82, pp.362-368. 10.1016/j.corsci.2014.01.036 . hal-01005718

\section{HAL Id: hal-01005718 \\ https: / hal.sorbonne-universite.fr/hal-01005718}

Submitted on 23 Oct 2014

HAL is a multi-disciplinary open access archive for the deposit and dissemination of scientific research documents, whether they are published or not. The documents may come from teaching and research institutions in France or abroad, or from public or private research centers.
L'archive ouverte pluridisciplinaire HAL, est destinée au dépôt et à la diffusion de documents scientifiques de niveau recherche, publiés ou non, émanant des établissements d'enseignement et de recherche français ou étrangers, des laboratoires publics ou privés. 


\title{
Contribution of electrochemical dissolution during pickling of low carbon steel in acidic solutions
}

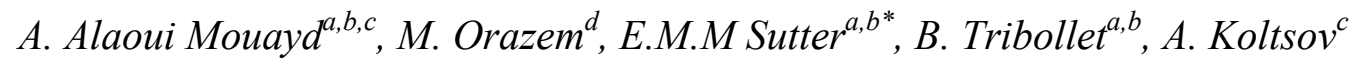

${ }^{a}$ Sorbonne Universités, UPMC Univ Paris 06, UMR 8235, Laboratoire Interfaces et Systèmes Electrochimiques, F-75005, Paris, France

${ }^{b}$ CNRS, UMR 8235, LISE, F-75005, Paris, France

${ }^{c}$ ArcelorMittal Maizières Research, voie Romaine, F-57280, Maizières-lès-Metz, France

${ }^{d}$ Chemical Engineering Dpt, University of Florida, Gainesville, FL, USA

\begin{abstract}
An electrochemical cell coupled with ICP-OES chemical analysis was used to explore the role of chemical and electrochemical reactions in pickling of low carbon steel in acidic media. Impedance spectroscopy was used to highlight scale properties. Dissolution of hematite is shown to be mainly of chemical nature, whereas the dissolution of magnetite and wüstite is both chemical and electrochemical. Initially, chemical dissolution of the scale dominated. The electrochemical reactions included oxidation of magnetite and wüstite and reduction of ferric ions formed by chemical dissolution. After the electrolyte reached the steel substrate, electrochemical dissolution of the iron was the main reaction.
\end{abstract}

\section{Key words:}
A. Low alloy steel
B. ICP-OES
B. EIS
C. Acid corrosion

\section{Introduction}

Removal of scale from a steel surface concerns important industrial processes. In the hot strip mill process, steel surface is in contact with humid air at high temperatures, from nearly $1200^{\circ} \mathrm{C}$ (reheating furnace) to nearly $700^{\circ} \mathrm{C}$ (coiling). In these conditions, an oxide layer called commonly "scale" is formed [1]. It is usually removed by dissolution in an acid bath to recover a clean, bare, and smooth steel surface compatible with surface quality requirements. For non alloyed steels, scale is mainly composed of a mixture of iron oxides, 
which are soluble in pickling baths such as hydrochloric acid. The challenging aim of this process is to remove the scale completely without dissolving and thus roughening the steel substrate (over-pickling).

A good control of the dissolution process requires an accurate understanding of the mechanism of pickling and over-pickling. Such a study in real industrial conditions is difficult to be performed, since the pickling treatments on a mild steel fabrication line is very rapid, usually less than one minute. Another problem for such a study is the need to obtain welldefined systems reproducing the industrial scale composition, i.e. continuous parallel sublayers deposited on the substrate and made of wüstite $(\mathrm{FeO})$, magnetite $\left(\mathrm{Fe}_{3} \mathrm{O}_{4}\right)$ and hematite $\left(\mathrm{Fe}_{2} \mathrm{O}_{3}\right)$ [2] . In order to obtain information on the behaviour of passive films, a large amount of work has been carried out on pure iron oxides (bulk oxides, sintered powders or sputtered layers on a membrane) [3-9], and it has been shown that the electronic properties of synthetic iron oxides are in good agreement with the behaviour of natural passive films on iron. Compared to the large amount of data on the mechanism of pure iron oxide dissolution, there is much less information available on the dissolution of oxides from steel surface. In reference [10], oxides have been thermally formed on steel in different atmospheres and were only characterized in their initial state in a neutral medium. They have been shown to consist of an inner magnetite scale covered by a hematite layer, both with semiconducting properties that could be varied significantly by changing the atmosphere during thermal treatment.

Since it is known that iron oxide dissolution in acid solutions is simultaneously a chemical and an electrochemical process [5, 7-9], another difficulty is to find experimental methods which allow the two mechanisms to be distinguished. While electrochemical methods provide information on the rate of electrochemical dissolution, additional analytical techniques are necessary to determine the total dissolution rate. In reference [5, 7], in situ Xray absorption near-edge spectroscopy (XANES) has been used simultaneously with electrochemical methods on synthetic oxide to determine the nature of the dissolution reaction, leading to the conclusion that dissolution of hematite and magnetite is mainly chemical in the anodic potential range, and that electrochemical dissolution of magnetite has to be taken into account in the cathodic range. Inductively coupled plasma-atomic emission spectroscopy (ICP-OES) has been shown to be a useful method for the in situ determination of material dissolution, using solution analysis in a flow cell [11-13]. A similar approach was used in the present work on oxide layers grown on a steel substrate. In order to reproduce the composition of the scale obtained in a hot strip mill, the oxide layer was thermally grown in a furnace. Electrochemical methods such as polarization curves and impedance spectrometry 
were applied to estimate the rate of electrochemical dissolution, whereas the overall rate of iron dissolution in the pickling solution was followed in situ, using an analytical set-up composed of an inductively coupled plasma optical emission spectrometer (ICP-OES) placed downstream from the electrochemical flow. To allow measurements at a reasonable time scale, a 1 molar hydrochloric acid solution was used as pickling solution ( 1 to $3 \mathrm{M}$ in industrial conditions) and all the experiments were performed at $20^{\circ} \mathrm{C}$ (instead of 50 to $90^{\circ} \mathrm{C}$ ), assuming that a temperature increase does not modify the mechanisms, but only the rate of the reactions. Addition into the pickling bath of inhibitors often used on industrial lines was not considered in the present work and could be the aim of a future paper.

From the comparison between the electrochemical dissolution rate and the rate of total iron enrichment in the pickling bath, estimation of the chemical dissolution rate could be performed.

\section{Experimental}

\section{Sample Elaboration:}

A disc of $25 \mathrm{~mm}$ diameter was extracted from a low carbon steel black coil sheet and ground with $\mathrm{SiC}$ paper to a grit of 800 on both faces to remove scale and rust of hot rolling. The composition of the low carbon steel sample under investigation is given in Table 1.

\section{Oxidation process}

The oxidation process was conducted in an Orion ${ }^{\circledR}$ Pilot furnace. Both disc surfaces of all samples were ground with a SiC-paper to a grit of 800, cleaned in ethanol and then dried in air before oxidation tests. The samples were heated in a nitrogen atmosphere at a rate of $40^{\circ} \mathrm{C} / \mathrm{min}$. The rate was reduced to $5^{\circ} \mathrm{C} / \mathrm{min}$ for the last $50^{\circ} \mathrm{C}$ to avoid exceeding the desired oxidation temperature. Once the desired temperature was reached, the oxidation was isothermal at temperature $850^{\circ} \mathrm{C}$ with $15 \%$ relative humidity for duration of 15 minutes. The pilot furnace chamber was subsequently cooled in a $\mathrm{N}_{2}$ atmosphere to room temperature at a rate of $40^{\circ} \mathrm{C} / \mathrm{min}$. The whole oxidation process is described in [14].

\section{Electrochemical measurements}

A classical three-electrode cell immerged in an air-saturated acid bath $\left(\mathrm{HCl} 1 \mathrm{~mol} \mathrm{~L}^{-1}\right)$ cell was used for pickling and over-pickling experiments at room temperature $\left(20^{\circ} \mathrm{C}\right)$. A 
saturated calomel electrode and a platinum electrode were used as reference and auxiliary electrodes, respectively. The oxidized disk electrode was integrated in a sample-holder, with the scale covered face in contact with the electrolyte. The back-face was polished to ensure good electrical contact with the stainless steel central piece of the sample holder. An electrochemical interface (Solartron SI 1287) and a frequency response analyzer (Solartron 1250) were monitored by a computer using Zware and Zplot software for electrochemical measurements. Impedance experiments were performed over frequencies ranging from 65 $\mathrm{kHz}$ to $0.2 \mathrm{~Hz}$, using a $10 \mathrm{mV}$ sinusoidal potential modulation peak to zero. The potential scan rate for the potentiodynamic experiments was $1 \mathrm{mV}^{-1}{ }^{-1}$. All the electrochemical tests were performed in static conditions (rotation rate $=0 \mathrm{rpm}$ ).

\section{ICP-OES experiments}

An ICP-OES spectrometer, located in the ArcelorMittal Research centre, has been adapted for electrochemical experiments as described in detail by Ogle and Weber [15]. The coupling of a flow cell and ICP-OES spectrometer allows the multi-element analysis in the electrolyte downstream from a dissolution cell, but, in the present case, only the iron concentration was followed. The spectrometer is a commercial apparatus from Jobin-Yvon, Inc. (Ultima 2000) using a polychromator, an argon plasma source consisting of a $40 \mathrm{MHz}, 1$ $\mathrm{kW}$ inductively coupled plasma, into which the electrolyte sample is continuously aspirated. In the flow cell used, the working electrode of the electrochemical cell was placed in a small compartment $(0.2 \mathrm{~mL}$ of electrolyte), which is separated by a membrane from an adjacent compartment containing the reference. The electrolyte passed through the cell with a flow rate of about $2 \mathrm{~mL} / \mathrm{min}$, and the iron composition of the electrolyte was measured in real time. Previous calibration of the set-up allowed the establishment of the relationship between dissolution rate and concentration, taking into account the time resolution of the hydraulic system. The detailed procedure is described in reference [15]. The sample surface in contact with the electrolyte was $5 \times 15 \mathrm{~mm}^{2}$.

\section{Results}

\section{Scale characterisation}

After oxidation in the pilot furnace, the samples were moulded in a cold resin and ground with SiC-paper to a grit of 4000 to obtain cross-section micrographs. The resulting 
steel scale was homogenous and was essentially composed of wüstite covered by a magnetite layer (Figure 1a). The mean thickness of the scale was about $70 \mu \mathrm{m}$. Below $570^{\circ} \mathrm{C}$, wüstite is known to be unstable and to transform into iron and magnetite eutectoid [16,17]. However, this transformation needs very low cooling rates, and, since in these experiments the cooling rate was about $40{ }^{\circ} \mathrm{C} / \mathrm{min}$, it can be assumed that this transformation only affected a small part of the scale volume $[14,15]$.

On the top of the scale surface, Raman analysis shown in Figure $1 \mathrm{~b}$ revealed the presence of a hematite layer with intense peaks at $220 \mathrm{~cm}^{-1}, 290 \mathrm{~cm}^{-1}$ and $410 \mathrm{~cm}^{-1}$, as well as small peaks at 500 and $610 \mathrm{~cm}^{-1}$. This hematite layer was very thin and not visible on SEM micrograph of sample cross-section.

Raman characterizations performed on cross-section did not allow clear differentiation of magnetite and wüstite. The Raman spectrum obtained on the external layer corresponds well to the spectrum of magnetite $\left(\mathrm{Fe}_{3} \mathrm{O}_{4}\right)$ with characteristic peaks at $310 \mathrm{~cm}^{-1}, 540 \mathrm{~cm}^{-1}$ and $670 \mathrm{~cm}^{-1}$ (Figure $1 \mathrm{~b}$ ). The wüstite phase $(\mathrm{FeO})$ is cubic and should not be visible on Raman. However, a peak at $660 \mathrm{~cm}^{-1}$ was observed from the Raman analyses of the internal layer (Figure 1b) [18, 19]. This peak could be due to the presence of lacunas in wüstite microstructure (wüstite $\mathrm{Fe}_{1-\mathrm{x}} \mathrm{O}$ with relatively large $x$ variation according to the phase diagram [17]) or partial wüstite transformation during cooling into $\mathrm{Fe}+\mathrm{Fe}_{3} \mathrm{O}_{4}$ eutectoid (presence of magnetite areas).

EDS analyses of the steel sample cross-section shown in Figure 1a confirmed the chemical composition of the scale layers. The Fe:O elements ratios of 43.6:56.4 for the external layer and 49.4:50.6 for the internal layer correspond to magnetite and wüstite, respectively. The minor alloying elements shown in Table 1, are present at too low concentrations to be observed by EDS. It has been shown that some alloying elements, mainly $\mathrm{Mn}$ and $\mathrm{Si}$, can have a huge effect on the acid reactivity of the scale [13], but their concentrations in the present work is much lower than in [13]. Their influence on pickling rate was therefore not considered.

The presence of the two external layers with iron oxidation degrees higher than that of wüstite comes from the continuous oxidation of iron diffusing through cationic vacancies in wüstite towards the outer scale layer, which is more concentrated in oxygen [20].

Increased oxidation temperature and duration increased scale thickness. For very high oxidation temperatures and durations, a thicker magnetite layer appeared above the transformed wüstite $[2,21]$. 


\section{Electrochemical experiments at steady state}

\subsection{Open Circuit Potential}

From an experimental point of view, the open circuit potential of the sample during the pickling process is easy to follow. The results are given in Figure 2. At the beginning of immersion, the open circuit potential (OCP) was well defined and had a value of about +0.4 V/SCE. Such a positive value has also been reported for sputtered hematite and magnetite and was attributed to a passive-like behaviour [7]. During the first 6 hours of immersion, the OCP decreased to $+0.15 \mathrm{~V} / \mathrm{SCE}$ and then increased again to $+0.3 \mathrm{~V} / \mathrm{SCE}$. This value was maintained for a period of 6 hours, after which an almost instantaneous jump was observed to a value of $-0.45 \mathrm{~V} / \mathrm{SCE}$, which is close to the OCP measured on bare steel in the same electrolyte. After the jump the OCP kept a roughly constant value.

\subsection{Corrosion current density measurements}

Exploratory potentiodynamic measurements were first performed in the anodic and cathodic potential ranges, showing Tafel behaviour in the cathodic range (not shown). The corrosion current density $(I)$ could then easily be determined from cathodic domain by extrapolating $\log I$ to the OCP.

Every 0.5 hour, current density-potential curves were recorded around the OCP, starting from $(\mathrm{OCP}+100 \mathrm{mV})$ towards $(\mathrm{OCP}-100 \mathrm{mV})$ at a $1 \mathrm{mV} \mathrm{s}^{-1}$ scan rate. Though this method is very approximate and that extrapolation of the Tafel line in a potential range close to the open-circuit potential can lead to inaccurate values for the corrosion rate, the goal was to provide short-time measurements throughout the pickling process. Moreover this restricted potential range allows avoiding significant modification of the scale by polarization. Three examples of these curves are given in Figure 3. In addition, the current density-potential curves for a steel electrode without oxide are also plotted as a reference, leading to an estimate of $80 \mu \mathrm{A} / \mathrm{cm}^{2}$ for the corrosion current density $\left(E_{\text {corr }}=-0.5 \mathrm{~V} / \mathrm{SCE}\right)$.

The corrosion current density determined from current-potential curves is also plotted as a function of immersion time in Figure 2. At the beginning of immersion, the corrosion current density was very low, with a value of about $50 \mathrm{nA} \mathrm{cm}$. This low value is in agreement with the presence of a hematite layer and with the value usually measured in the presence of a passive layer. The current increases monotonically, up to the potential jump which is observed after 12 hours. The increase in the corrosion current density is likely to be linked to the decrease of the area protected by the hematite and to the penetration of the 
electrolyte in the oxide layer. It is noticeable that after 12 hours of immersion the corrosion current density reached a value of $1 \mathrm{~mA} / \mathrm{cm}^{2}$ and kept about the same value after the potential jump. This result is surprising, because due to the potential jump of about $700 \mathrm{mV}$ the electrochemical reactions are normally expected to be completely different before and after the potential jump. As shown in Figure 2, within a period of 12 hours of immersion, the corrosion current density increased by more than 4 orders of magnitude passing from $50 \mathrm{nA}$ $\mathrm{cm}^{-2}$ to $1 \mathrm{~mA} \mathrm{~cm}^{-2}$.

\section{Electrochemical Impedance Spectroscopy}

During the immersion period, the electrochemical impedance was measured at the open-circuit potential every 15 minutes. A representative impedance spectrum, obtained after 15 minutes of immersion, is presented in Figure 4 in Nyquist format. The shape of the impedance diagram corresponds to a portion of a depressed semicircle. The lowest measured frequency was fixed to $0.2 \mathrm{~Hz}$ to enable measurement of the impedance diagram in period less than 2 minutes. This diagram was analyzed by use of an equivalent circuit composed of a resistor in parallel with a constant phase element CPE (inset of Figure 4). The impedance of the CPE is given by $Z_{\mathrm{CPE}}=\left(Q(\mathrm{j} 2 \pi)^{\alpha}\right)^{-1}$ where $\alpha$ and $Q\left(\mathrm{~F} \mathrm{~s}^{(\alpha-1)} \mathrm{cm}^{-2}\right)$ are the CPE parameters.

\subsection{Evolution of the polarisation resistance}

Similar to the variation of the corrosion current shown in Figure 2, the polarisation resistance varied by a few orders of magnitude within the immersion duration. For each immersion time, the CPE parameters $(Q$ and $\alpha)$ and the polarisation resistance $(R)$ were obtained by a regression procedure using the software SIMAD developed in our laboratory. The inverse of the polarisation resistance $\left(R^{-1}\right)$ is presented as a function of the immersion time in Figure 5. If the polarisation resistance is assumed to be the charge transfer resistance, then the product of the corrosion current and charge transfer resistance should be proportional to the Tafel slope $\beta$, i.e., $R_{\mathrm{t}} I_{\text {corr }}=\beta / 2.303$.

The comparison between the temporal variation of $I_{\text {corr }}$ (Figure 2) and that of $R^{-1}$ shows some differences, since the charge transfer resistance varies over more than three decades; whereas, the corrosion current density varies over more than four decades. This difference could be due to the fact that, according to the dissolution time, the reactions involved in the different processes are different and then the value of the Tafel slope $\beta$ corresponding to the product $R_{\mathrm{t}} I_{\text {corr }}$ can vary with time. Moreover, as mentioned previously, the determination of 
$I_{\text {corr }}$ by the Tafel method in the vicinity of the $E_{\text {corr }}$ can lead to inaccurate corrosion rate values. Nevertheless the variation of the two parameters shows the same tendency.

\subsection{Evolution of the CPE parameters}

The variation of parameters $Q$ and $\alpha$ are presented as a function of the immersion time in Figure 6. The $\alpha$ values are in the range 0.8 to 0.9 within the duration of the experiment, indicating that the CPE can be attributed to a capacitance. Two domains are clearly observed for the $Q$ values: during the first 6 hours, $Q$ had a steady value of about $10 \mu \mathrm{F} . \mathrm{s}^{\alpha-1} . \mathrm{cm}^{-2}$, a

jump was observed, after which $Q$ had a roughly constant value of $1 \mathrm{mF} \cdot \mathrm{s}^{\alpha-1} \cdot \mathrm{cm}^{-2}$ until the end of the experiment. Figure 6 shows that the jump in $Q$ is observed at the point in time where the evolution of OCP slightly reverses (Figure 2). The low $Q$ value at short immersion times shows characteristics of a thin dielectric layer and was therefore attributed to the hematite layer. After 6 hours the huge increase in $Q$ value leads to capacitance values incompatible with a dielectric compact film and was therefore associated with a double layer capacitance on a conducting porous layer such as magnetite. It is noticeable that no significant $Q$ variation is observed before and after the potential jump at 12 hours.

\section{ICP-OES measurements}

The dissolution rate of iron from the scale covered steel samples was measured by ICP-OES during the pickling process, and the overall variation $\mathrm{Fe}(\mathrm{ICP})$ with time is shown in Figure 7. The evolution of the open-circuit potential $E(\mathrm{ICP})$ was measured simultaneously. Its overall evolution is in agreement with the overall evolution observed during electrochemical measurements $E(\mathrm{EC})$, which is also reported in Figure 7. It appears that during the ICP-OES experiment, the experimental potential versus time curve shows a very smooth transition without the small potential jump observed at 6 hours during electrochemical experiments. The difference can be attributed to different hydrodynamic conditions in the two types of experiments, since ICP-OES experiments use a flow cell, whereas electrochemical measurements were performed in still solutions. Moreover $E(\mathrm{EC})$ values were taken every 0.5 $\mathrm{h}$ in stationary conditions, whereas $E(\mathrm{ICP})$ was followed continuously as a function of time.

Similarly to $E(\mathrm{EC}), E(\mathrm{ICP})$ had a very anodic value (about $0.4 \mathrm{~V}$ ) at the beginning of the dissolution process, followed by an abrupt drop towards $-0.5 \mathrm{~V}$ after several hours. For easier comparison between electrochemical results and ICP measurements, a dimensionless time $t / \tau$ is reported on the abscissa of Figure 7, which is defined as the ratio between the 
elapsed time and the time $\tau$ corresponding to the potential jump. Moreover, from the corrosion current densities reported in Figure 2 the electrochemical dissolution rate $\mathrm{Fe}(\mathrm{EC})$ calculated using Faraday's law (taking one electron as a first approximation) is also reported for comparison with the total rate of iron dissolution.

\section{Discussion}

During the early stages of immersion, the OCP was $0.4 \mathrm{~V} / \mathrm{SCE}$ and the corrosion current density was very low, i.e., $50 \mathrm{nA} \mathrm{cm}^{-2}$. The Raman spectra suggest that the oxide layer at this stage was coated by a very thin layer of hematite. In agreement with the positive value of the OCP and the low value of the corrosion current, the hematite showed a passivating layer, with field-assisted transfer of ions within the semiconducting non-stoechiometric layer [7].

The existence of some cracks in the hematite leading to a contact between the solution (1M HCl) and $\mathrm{Fe}_{3} \mathrm{O}_{4}$ and/or $\mathrm{FeO}$ cannot be excluded, but, since $\mathrm{Fe}_{2} \mathrm{O}_{3}$ and $\mathrm{Fe}_{3} \mathrm{O}_{4}$ layers have very close OCP potential values in acid solutions [7], the contribution of each component cannot be determined. It clearly appears from Figure 7 that at this stage of pickling the hematite layer mainly dissolves by a chemical process, with an electrochemical contribution of $0.1 \%$, in close agreement with the results of Virtanen et al. [7].

During the first hours, $t / \tau<1$, the corrosion current density stayed at a very low level, whereas the open-circuit potential and the overall leaching rate were roughly constant. This period of time could be characteristic of the vanishing of the hematite layer due to chemical dissolution according to

$$
\mathrm{Fe}_{2} \mathrm{O}_{3}+6 \mathrm{H}^{+} \rightarrow 2 \mathrm{Fe}^{3+}{ }_{(\mathrm{aq})}+3 \mathrm{H}_{2} \mathrm{O}
$$

After this period, the increase in the electrochemical dissolution $\left(v_{\text {elec }}\right)$ rate became much more significant than that of total dissolution rate $\left(v_{\text {total }}\right)$, the ratio between $v_{\text {elec }} / v_{\text {total }}$ passing from $1 / 1000$ to $1 / 4$ after a pickling time close to $t / \tau=1$. Before $t / \tau=1$, the corrosion potential progressively decreases from 0.5 to $0.3 \mathrm{~V}$, simultaneously with the increase of the electrochemical dissolution of the remaining phases beneath hematite, mainly magnetite and wüstite. The overall leaching rate varied from 0.3 to $3 \mathrm{nmol} \mathrm{Fe} \mathrm{cm} \mathrm{s}^{-2}$ for $t / \tau$ varying from 0 to 1, which is two orders of magnitude higher than the value reported by Virtanen et al. [7] for pure hematite and pure magnetite, showing that the reactivity of the present scale is different from that of pure oxides. 
According to the previous observation, the CPE measured by impedance must correspond to the capacitance of the hematite layer for $t / \tau<0.25$, and to a double layer capacitance for larger immersion time. For each model the CPE analysis is different. In presence of the hematite layer, the time-constant distribution is through the hematite layer, and the recently proposed power-law model can be applied [22, 23]. When the hematite layer is dissolved, an electrochemical dissolution of the magnetite and wüstite is assumed. In this case the CPE corresponds to a double layer capacitance and the time constant distribution is along the surface in agreement with the hypothesis of Brug's formula [24].

For an immersion time smaller than about 6 hours, the hematite layer is present (Figures 2, 5, 6), and, according to the power law model [22, 23], the $\mathrm{Q}$ and $\alpha$ parameters are linked to physical parameters and, in particular,

$$
Q=\frac{\left(\varepsilon \varepsilon_{0}\right)^{\alpha}}{g \delta \rho_{\delta}^{1-\alpha}}
$$

where $g$ is a numerical function given by: $g=1+2.88(1-\alpha)^{2.375}, \delta$ is the oxide layer thickness, $\rho_{\delta}$ is the resistivity of the oxide at the oxide-solution interface, $\varepsilon$ is the dielectric constant of the hematite, and $\varepsilon_{0}$ is the permittivity of vacuum, given as $8.85 .10^{-14} \mathrm{~F} / \mathrm{cm}$. As

$$
C=\frac{\varepsilon \varepsilon_{0}}{\delta}
$$

the effective capacitance $C$ can be estimated from the CPE parameters, i.e.,

$$
C=\left(\varepsilon \varepsilon_{0}\right)^{1-\alpha} g Q \rho_{\delta}^{1-\alpha}
$$

The dielectric constant $\varepsilon$ is known and has a value of 12 for hematite [25]. The function $g$ is easily calculated with the experimental $\alpha$ value, and following Orazem et al. [26], a value of $500 \Omega \mathrm{cm}$ can be assigned for $\rho_{\delta}$.

Thus, from the experimental values of $Q$ and $\alpha$, values for the capacitance can be determined. The corresponding results are presented in Figure 8. The capacitance increased from $0.1 \mu \mathrm{F} \mathrm{cm}^{-2}$ to $0.5 \mu \mathrm{F} \mathrm{cm}^{-2}$. Following equation (3), these capacitance values correspond to a layer thickness which varies from $100 \mathrm{~nm}$ to $20 \mathrm{~nm}$. The small values of film thickness can be used to explain why, in the SEM micrograph presented in Figure 1, the hematite layer cannot be observed. 
For immersion times higher than 6 hours, the hematite layer is no longer present, and the corresponding double layer capacitance was calculated by applying Brug's formula [24] with Rs « R.

$$
C=\left(R_{s} Q_{0}\right)^{1 / \alpha} / R_{s}
$$

where $R_{s}$ is the resistance of the electrolyte . The double layer capacitance varied from $60 \mu \mathrm{F}$ $\mathrm{cm}^{-2}$ to $800 \mu \mathrm{F} \mathrm{cm}$ (Figure 8). These values are very large, but, if we assume that the solution penetrates inside the oxide layer, the active area can be significantly increased. So taking the usual value of $40 \mu \mathrm{F} \mathrm{cm}^{-2}$ for the double layer capacitance, the real active surface would be ascertained to be 1.5 to 20 times larger than the geometrical area. This temporal evolution of the active area is in agreement with the increase of the corrosion current density value passing from $10 \mu \mathrm{A} \mathrm{cm}^{-2}$ after 7 hours, to $1 \mathrm{~mA} \mathrm{~cm}^{-2}$ after $12 \mathrm{~h}$ of immersion.

\section{Potential jump at $t / \tau=1$ :}

At $t / \tau=1$, the huge potential jump from $0.3 \mathrm{~V} / \mathrm{SCE}$ to $-0.45 \mathrm{~V} / \mathrm{SCE}$ indicates that the electrochemical reactions involved before the jump no longer fix the corrosion potential value after the jump. It is then necessary to propose two sets of electrochemical equations, one set for the anodic domain before the jump and one set after.

Before the jump, after dissolution of hematite, the layer under consideration is mainly composed of magnetite and wüstite. As mentioned previously, wüstite is unstable at room temperature and is partly decomposed into iron and magnetite. At this anodic potential $(0.3$ $\mathrm{V} / \mathrm{SCE}$ ), the anodic dissolution of iron is very fast but the quantity of iron is small. The electrochemical reactivity of the layer must therefore be attributed to the electrochemical oxidation of magnetite according to

$$
\mathrm{Fe}_{3} \mathrm{O}_{4}+8 \mathrm{H}^{+} \rightarrow 3 \mathrm{Fe}^{3+}+4 \mathrm{H}_{2} \mathrm{O}+\mathrm{e}^{-}
$$

or to oxidation of wustite according to

$$
\mathrm{FeO}+2 \mathrm{H}^{+} \rightarrow \mathrm{Fe}^{3+}+\mathrm{H}_{2} \mathrm{O}+\mathrm{e}^{-}
$$

It has been suggested in the literature [7] on a pure sputtered magnetite layer that dissolution of magnetite is mainly chemical and that oxidative dissolution is not likely to occur. The main reaction leading to chemical dissolution of magnetite would then be

$$
\mathrm{Fe}_{3} \mathrm{O}_{4}+8 \mathrm{H}^{+} \rightarrow 2 \mathrm{Fe}^{3+}+\mathrm{Fe}^{2+}+4 \mathrm{H}_{2} \mathrm{O}
$$

In the present work, the composition of the scale beneath the hematite is a poorly-defined mixture of magnetite, wustite, and iron. It can also be expected that this layer is heterogeneous and defective and that the composition of the scale/solution interface is 
modified throughout the dissolution. Figure 7 shows clearly that chemical dissolution is significantly favoured as compared to the electrochemical process, but this latter step cannot be neglected and becomes significant after a few hours of pickling. This observation is supported by the interfacial capacitance value shown in Figure 8, which is in agreement with that of a double layer capacitance.

For the cathodic reaction, the potential is too anodic to consider the proton reduction, but, due to the parallel chemical dissolution of the oxides layer, the solution contains $\mathrm{Fe}^{3+}$ ions which can be reduced to $\mathrm{Fe}^{2+}$.

$$
\mathrm{Fe}^{3+}+\mathrm{e}^{-} \rightarrow \mathrm{Fe}^{2+}
$$

When the potential drop reaches the value of $-0.45 \mathrm{~V} / \mathrm{SCE}$, which is also the $E_{\text {corr }}$ value for bare iron in the acidic medium, the solution has reached the metal. The anodic reaction is then expected to be mainly iron dissolution according to:

$$
\mathrm{Fe} \rightarrow \mathrm{Fe}^{2+}+2 \mathrm{e}^{-}
$$

and the cathodic reaction is expected to be primarily proton reduction, i.e.,

$$
2 \mathrm{H}^{+}+2 \mathrm{e}^{-} \rightarrow \mathrm{H}_{2}
$$

Nevertheless visual observation of the surface of the sample shows that many spots of oxide are still present on the electrode even few hours after the potential jump, and Figure 7 confirms that chemical dissolution still contributes to the total dissolution.

Additional cathodic reactions should therefore be considered. According to references $[5,8,27]$, reductive dissolution of magnetite is also expected in this potential range, i.e.,

$$
\mathrm{Fe}_{3} \mathrm{O}_{4}+2 \mathrm{e}^{-}+8 \mathrm{H}^{+} \rightarrow 3 \mathrm{Fe}^{2+}+4 \mathrm{H}_{2} \mathrm{O}
$$

As before the potential drop the main cathodic reaction was assumed to be the reduction of $\mathrm{Fe}^{3+}$ ions coming from the chemical dissolution, the rate of this reaction should be highly enhanced at this cathodic potential. But since the contribution of the chemical process to the overall mechanism is significantly decreased, the concentration of $\mathrm{Fe}^{3+}$ near the surface is expected to be lowered too. The drastic decrease of the rate of chemical dissolution can be attributed to the fact that the rate of proton reduction is faster than the rate of chemical dissolution or to the fact that the production of hydrogen blocks the chemical dissolution of the oxide. The dissolution of iron is exclusively electrochemical and produces stable $\mathrm{Fe}^{2+}$ in this potential range.

\section{Conclusions}


In-situ ICP analysis of pickling solutions was performed in a flow-cell on scales synthetically obtained on low carbon steels. The results were compared to electrochemical dissolution rates determined on similar scales in static solutions, in order to estimate the contribution of the electrochemical mechanism to the overall dissolution reaction.

It appears that dissolution of hematite is mainly of chemical nature, whereas the dissolution of magnetite and wüstite is both chemical and electrochemical. A very positive open-circuit potential was measured in the presence of hematite and magnetite, but once the metallic substrate was reached by the pickling solution, a huge potential jump of more than $700 \mathrm{mV}$ towards the cathodic region was observed. Such a jump is only possible if the nature of the determining electrochemical reactions is drastically modified: before the potential jump, at $0.4 \mathrm{~V}$, the main anodic reaction is the oxidation of magnetite and wüstite and the main cathodic reaction the reduction of ferric ions formed by chemical dissolution. After the potential jump, at $-0.45 \mathrm{~V}$, the proton reduction is assumed to be the main cathodic reaction, whereas the oxidation of the iron substrate is the main anodic reaction. The reduction of ferric into ferrous ions must then become negligible, since the rate of chemical dissolution of iron oxide is significantly lowered in comparison with the electrochemical dissolution. A noticeable result in this work was to show the key role played by ferric ions formed in the pickling bath by chemical dissolution of hematite and magnetite. They provide the cathodic reaction enabling anodic dissolution of the scale, in a potential range in which protons are not reduced. The next step of this work could be to determine the impact of ferric ions on the electrochemical dissolution rate by adding ferric salts to the pickling solution.

\section{Acknowledgement}

Financial support for this work from ArcelorMittal is gratefully acknowledged. The University of Florida is acknowledged for hosting A. Alaoui. Mouayd for a short stay. 


\section{References}

[1] L. Chang, S.N. Lin, Analytical electron microscopy study of interfacial oxides formed on a hot-rolled low-carbon steel, Oxid. Met. 63 (2005) 131-144.

[2] J. Paidassi, Sur la cinétique de l'oxydation du fer dans l'air dans l'intervalle $700-1250^{\circ} \mathrm{C}$, Acta Metall. 6 (1958) 184-194.

[3] M. Büchler, P. Schmuki, H. Böhni, T. Stenberg, T. Mäntylä, Comparison of the semiconductive properties of sputter-deposited iron oxides with the passive film on iron, J. Electrochem. Soc. 145 (1998) 378-385.

[4] P. Schmuki, M. Büchler, S. Virtanen, H. Böhni, R. Müller, L. Gauckler, Bulk metal oxides as a model for the electronic properties of passive films, J. Electrochem. Soc. 142 (1995) 3336-3342.

[5] P. Schmuki, S. Virtanen, A.J. Davenport, C.M. Vitus, In situ X-Ray absorption near edge spectroscopic study of the cathodic reduction of artificial iron oxide passive films, J. Electrochem. Soc. 143 (1996) 574-582.

[6] S. Virtanen, P. Schmuki, H. Böhni, P. Vuoristo, T. Mäntylä, Artificial Cr-and Fe-oxide passive layers prepared by sputter deposition, J. Electrochem. Soc. 142 (1995) 3067-3972.

[7] S. Virtanen, P. Schmuki, A.J. Davenport, C.M. Vitus, Dissolution of thin iron oxide films used as models for iron passive films studied by in situ X-Ray absorption near edge spectroscopy, J. Electrochem. Soc. 144 (1997) 198-204.

[8] V.B. Fetisov, A.N. Ermakov, G.M. Belysheva, A.V. Fetisov, V.M. Kamyshov, K.Z. Brainina, Electrochemical dissolution of magnetite in acid solutions, J. Solid State Electrochem. 8 (2004) 565-571.

[9] W.W. Frenier, F.B. Growcock, Mechanism of iron oxide dissolution-A review of recent literature, Corrosion, 40 (1984) 663-668.

[10] J. Wielant, V. Goossens, R. Hausbrand, H. Terryn, Electronic properties of thermally formed thin iron oxide films, Electrochim. Acta 52 (2007) 7617-7625.

[11] D. Hamm, K. Ogle, C.-O. Olsson, S. Weber, D. Landolt, Passivation of Fe-Cr alloys studied with ICP-OES and EQCM, Corros. Sci. 44 (2002) 1443-1456.

[12] K. Ogle, A. Tomandl, N. Meddahi, M. Wolpers, The alkaline stability of phosphate coatings I: ICP atomic emission spectroelectrochemistry, Corros. Sci. 46 (2004) 979-995. 
[13] P. Volovitch, I. Gazizzullin, F. Ruel, K. Ogle, An atomic emission spectroelectrochemical study of corrosion inhibition: The effect of hexamethylenetetramine on the reaction of mild steel in $\mathrm{HCl}$, Corros. Sci.53 (2011) 1362-1368.

[14] A. Alaoui Mouayd, A. Koltsov, E. Sutter, B. Tribollet, Effect of silicon content in steel and oxidation temperature on scale growth and morphology, Materials Chemistry and Physics (2013), doi: http://dx.doi.org /10.1016/ j.matchemphys.2013.10.037.

[15] K. Ogle, S. Weber, Anodic dissolution of 304 stainless steel using atomic emission spectroelectrochemistry, J. Electrochem. Soc. 147 (2000) 1770-1780.

[16] R. Chen, W. Yeun, Review of the high-temperature oxidation of iron and carbon steels in air or oxygen, Oxid. Met. 59 (2003) 433-468.

[17] R. Chen, W. Yuen, A study of the scale structure of hot-rolled steel strip by simulated coiling and cooling, Oxid. Met. 53 (2000) 539-560.

[18] A. Chattopadhyay, N. Bandyopadhyay, A. Das, M. Panigrahi, Oxide scale characterization of hot rolled coils by Raman spectroscopy technique, Scripta Mater. 52 (2005) 211-215.

[19] M. Hanesch, Raman spectroscopy of iron oxides and (oxy) hydroxides at low laser power and possible applications in environmental magnetic studies, Geophys. J. Int. 177 (2009) 941948.

[20] H. Abuluwefa, R. Guthrie, J. Root, F. Ajersch, Real-time observations of the oxidation of mild steel at high temperature by neutron diffraction, Metall. Mater. Trans. B 27 (1996) 993997.

[21] Y.-L. Yang, C.-H. Yang, S.-N. Lin, C.-H. Chen, W.-T. Tsai, Effects of Si and its content on the scale formation on hot-rolled steel strips, Mater. Chem. Phys. 112 (2008) 566-571.

[22] B. Hirschorn, M.E. Orazem, B. Tribollet, V. Vivier, I. Frateur, M. Musiani, ConstantPhase-Element Behavior Caused by Resistivity Distributions in Films I. Theory, J. Electrochem. Soc. 157 (2010) C452-C457.

[23] B. Hirschorn, M.E. Orazem, B. Tribollet, V. Vivier, I. Frateur, M. Musiani, ConstantPhase-Element Behavior Caused by Resistivity Distributions in Films II. Applications, J. Electrochem. Soc. 157 (2010) C458-C463.

[24] G. Brug, A. Van Den Eeden, M. Sluyters-Rehbach, J. Sluyters, The analysis of electrode impedances complicated by the presence of a constant phase element, J. Electroanal. Chem. 176 (1984) 275-295.

[25] H. Frederikse, Permittivity (Dielectric Constant) of Inorganic Solids, in: CRC Handbook of Chemistry and Physics 2012-2013, CRC press, 2012. 
[26] M.E. Orazem, I. Frateur, B. Tribollet, V. Vivier, S. Marcelin, N. Pébère, A.L. Bunge, E.A. White, D.P. Riemer, M. Musiani, Dielectric properties of materials showing constantphase-element (CPE) impedance response, J. Electrochem. Soc. 160 (2013) C215-C225.

[27] P.D.Allen, N. A. Hampton, G.J. Bignold, The electrodissolution of magnetite, J. Electroanal. Chem. 99 (1979) 299-309. 


\section{FIGURE CAPTIONS}

Figure 1: Results of ex-situ surface analysis: a) Cross-section SEM micrograph of the steel sample after oxidation at $850^{\circ} \mathrm{C}$ in air with $15 \%$ relative humidity during 15 minutes; and b) Raman spectra of the scale phases: hematite external surface, magnetite layer and wüstite layer.

Figure 2: Evolution of the corrosion potential and corrosion current during scale dissolution in $1 \mathrm{M} \mathrm{HCl}$.

Figure 3: Examples of current-potential curves plotted for different immersion times, for scale covered and scale free steel electrodes $\left(v=1 \mathrm{mV} \mathrm{s}^{-1}\right)$.

Figure 4: Typical impedance diagram in Nyquist format measured after 15 minutes of immersion of the sample in $1 \mathrm{M} \mathrm{HCl}$ at the corrosion potential $(400 \mathrm{mV} / \mathrm{SCE})$. The dashed line corresponds to the fit line. The inset shows the equivalent-circuit used to analyse the spectrum

Figure 5: Temporal evolution of the inverse of the charge transfer resistance $\mathrm{R}^{-1}$ during scale dissolution in $1 \mathrm{M} \mathrm{HCl}$ acid solution.

Figure 6: Temporal evolution of regressed CPE parameters $\alpha$ and $Q$ during scale dissolution in $1 \mathrm{M} \mathrm{HCl}$ acid solution.

Figure 7: Comparison between the total scale dissolution rate measured by ICP-OES and the electrochemical dissolution rate in $1 \mathrm{M} \mathrm{HCl}$ solution and evolution with time of the OCP measured by the two methods.

Figure 8: Evolution of effective capacitance calculated with the power-law model [22] for a normal time-constant distribution and with Brug's model [24] for a surface time-constant distribution during dissolution of scale in $1 \mathrm{M} \mathrm{HCl}$. 


\begin{tabular}{llllllllll}
\hline Element & $\mathrm{C}$ & $\mathrm{Si}$ & $\mathrm{Mn}$ & $\mathrm{P}$ & $\mathrm{Cr}$ & $\mathrm{Ni}$ & $\mathrm{Cu}$ & $\mathrm{N}$ & $\mathrm{Fe}$ \\
\hline wt \% & 0.04 & $\mathbf{0 . 0 2}$ & $\mathbf{0 . 1 9}$ & $\mathbf{0 . 0 1}$ & $\mathbf{0 . 0 2 5}$ & $\mathbf{0 . 0 1 7}$ & $\mathbf{0 . 0 2 5}$ & $\mathbf{0 . 0 1}$ & balance \\
\hline
\end{tabular}

Table 1: Chemical composition of the steel as obtained by optical emission spectroscopy (OES) 

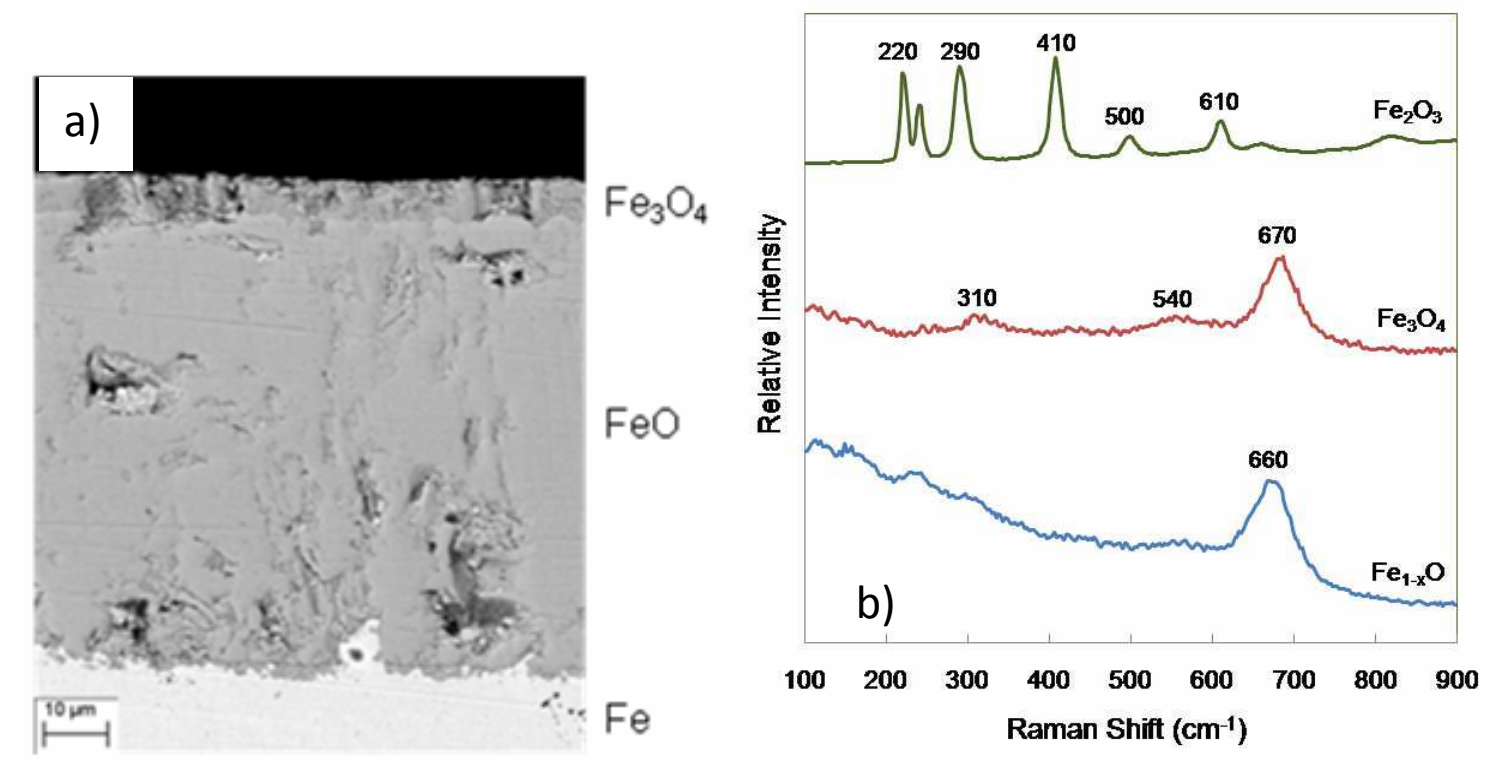

Figure 1 


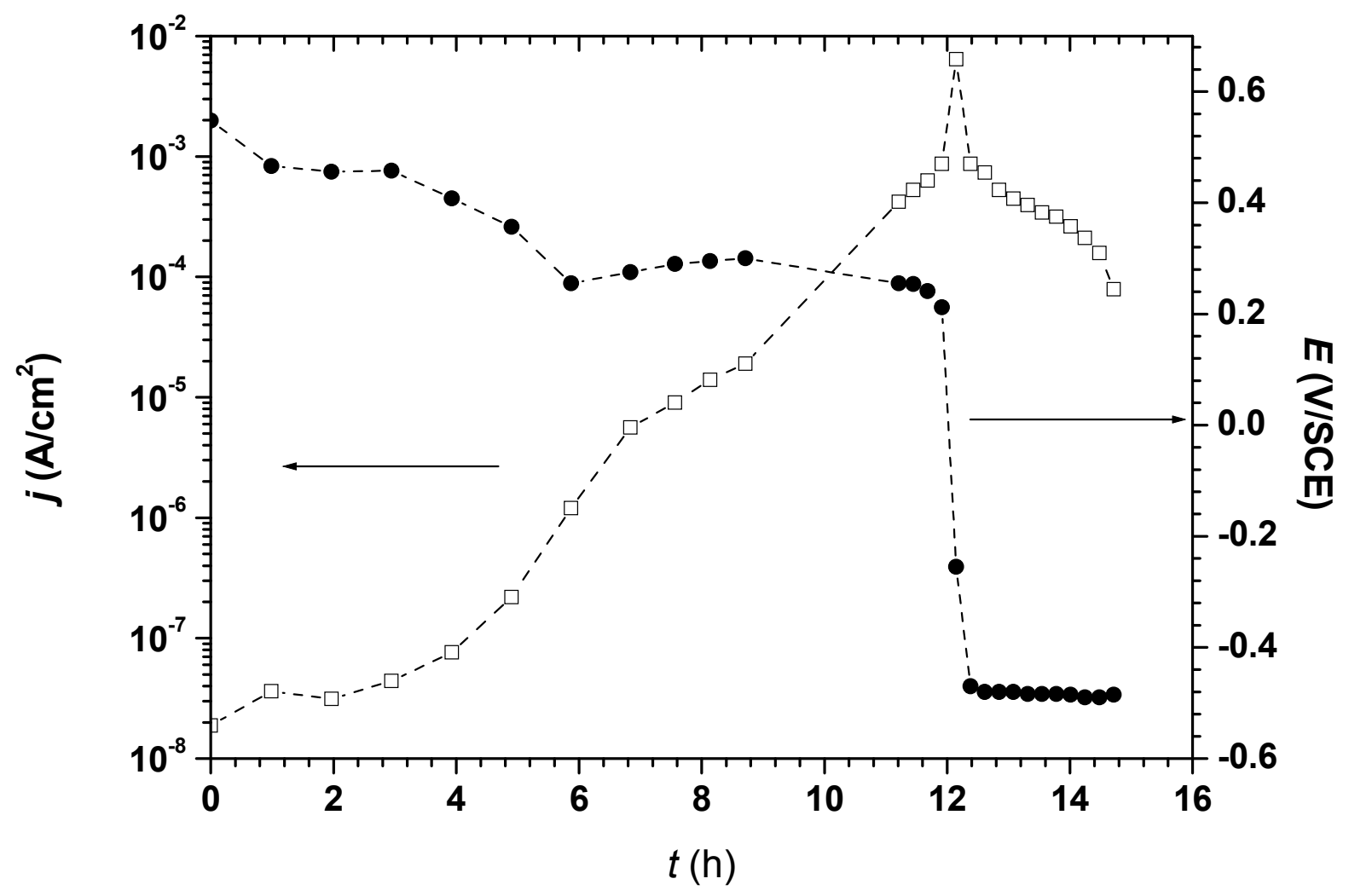

Figure 2 


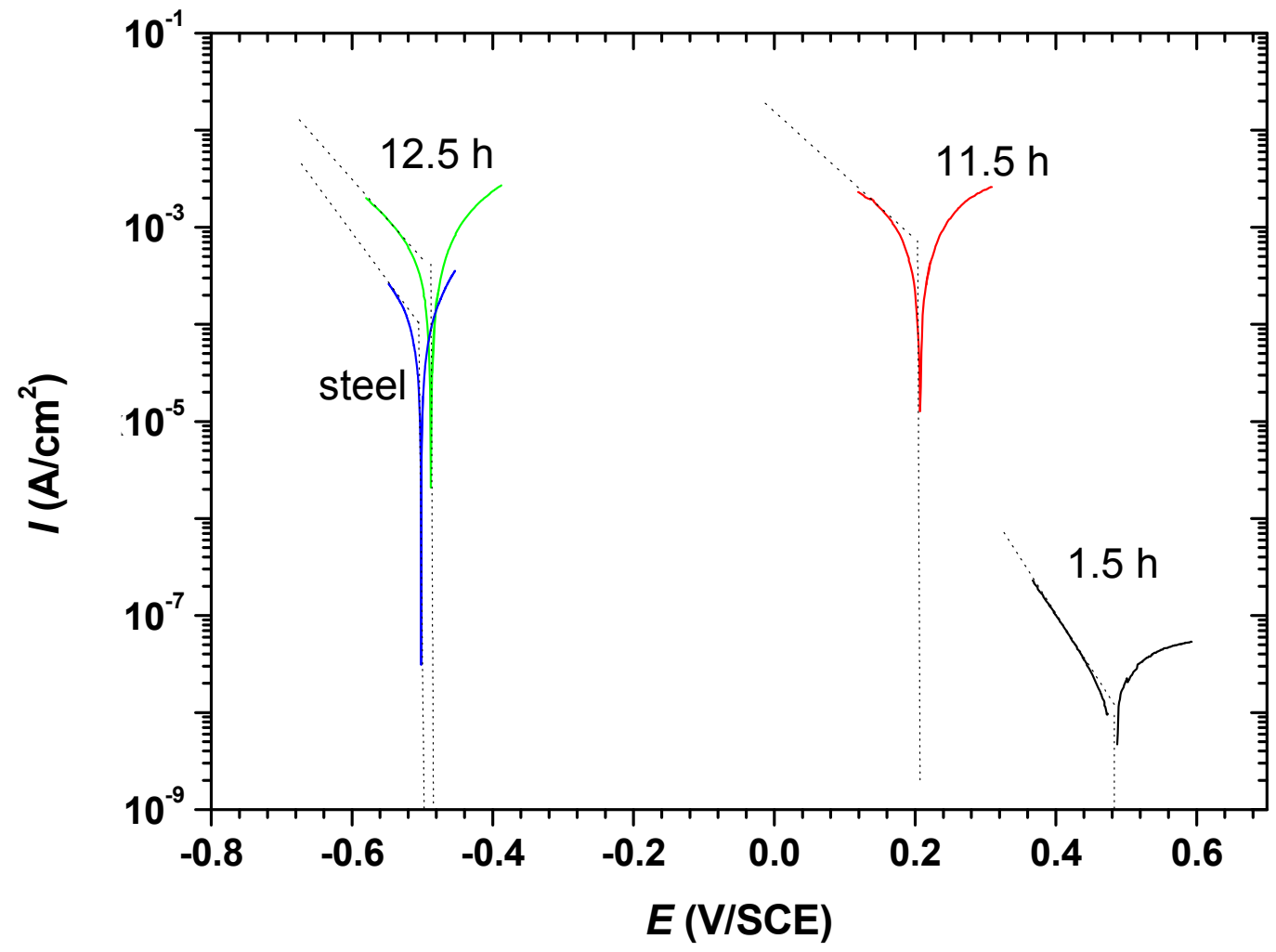

Figure 3 


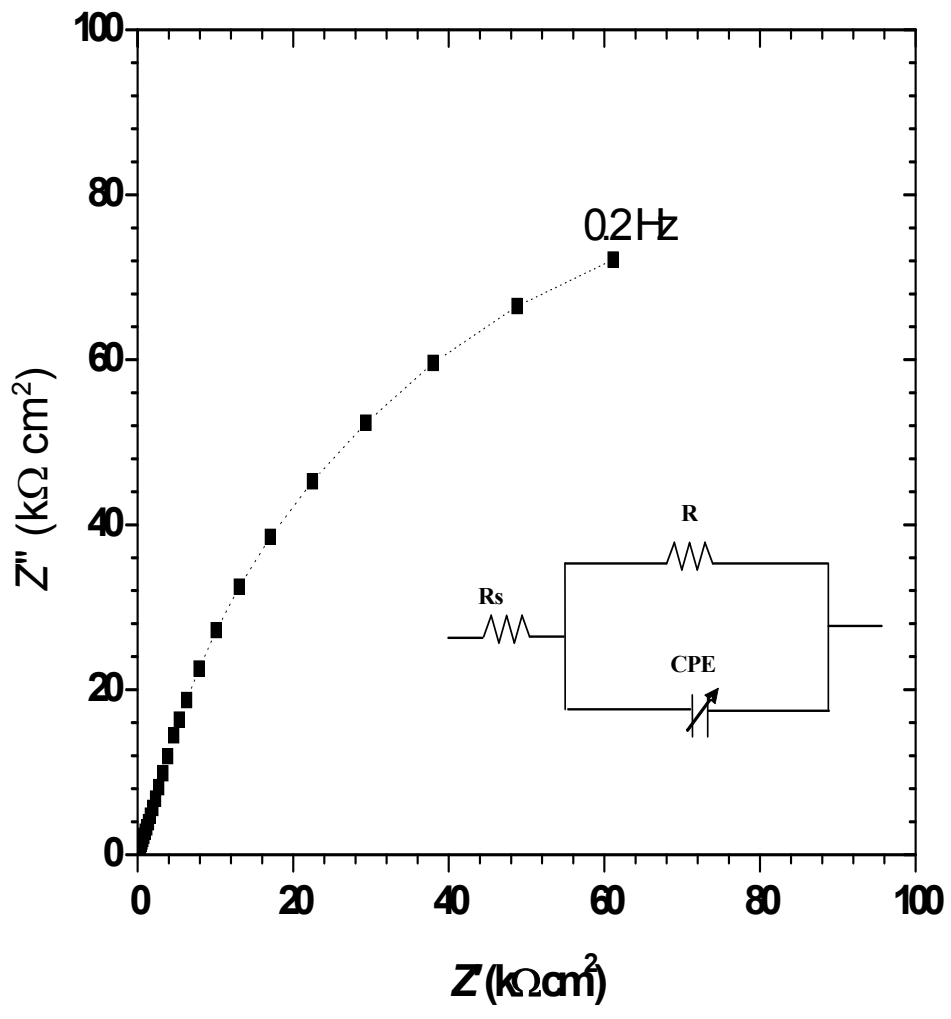

Figure 4 


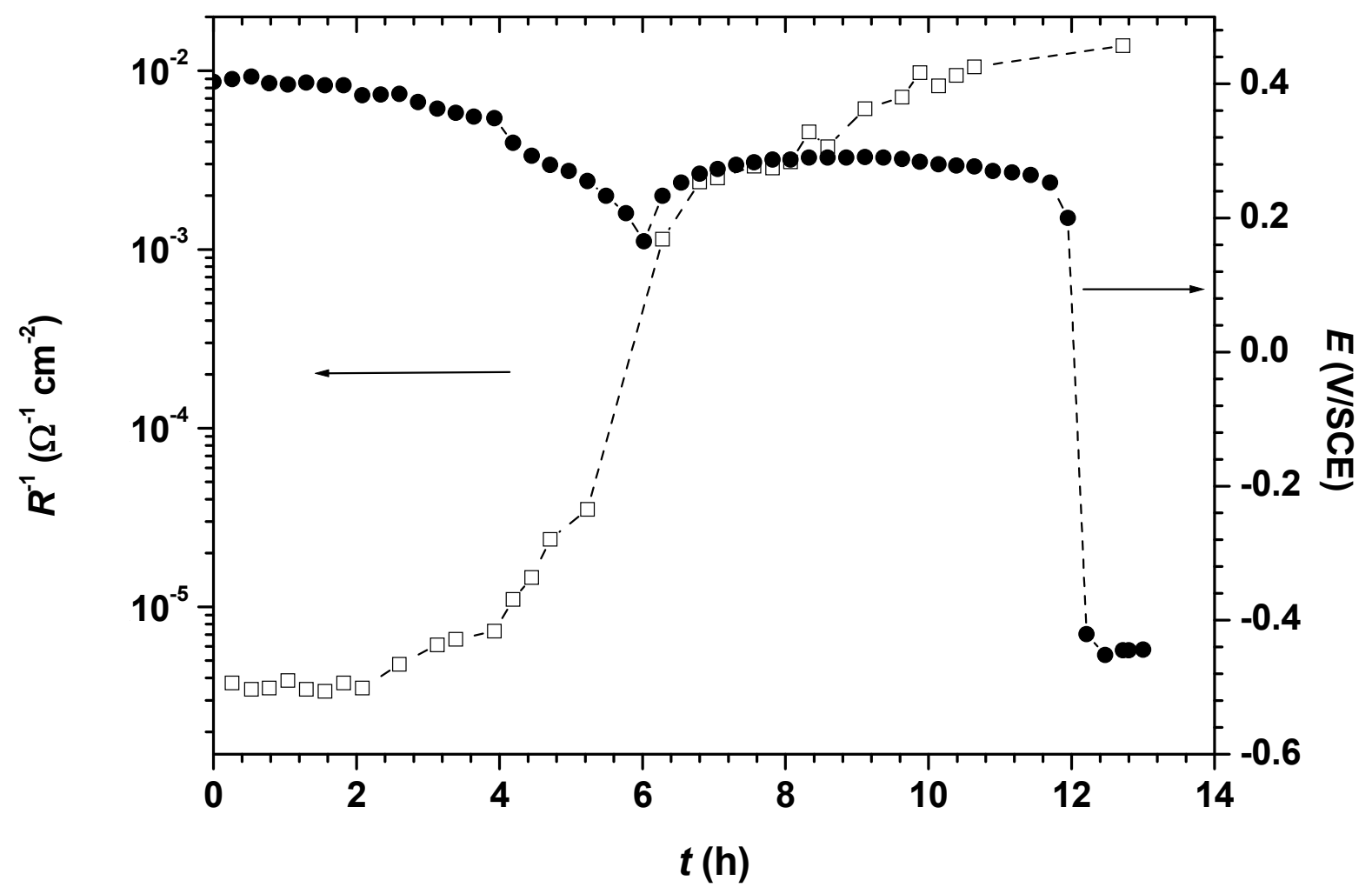

Figure 5 


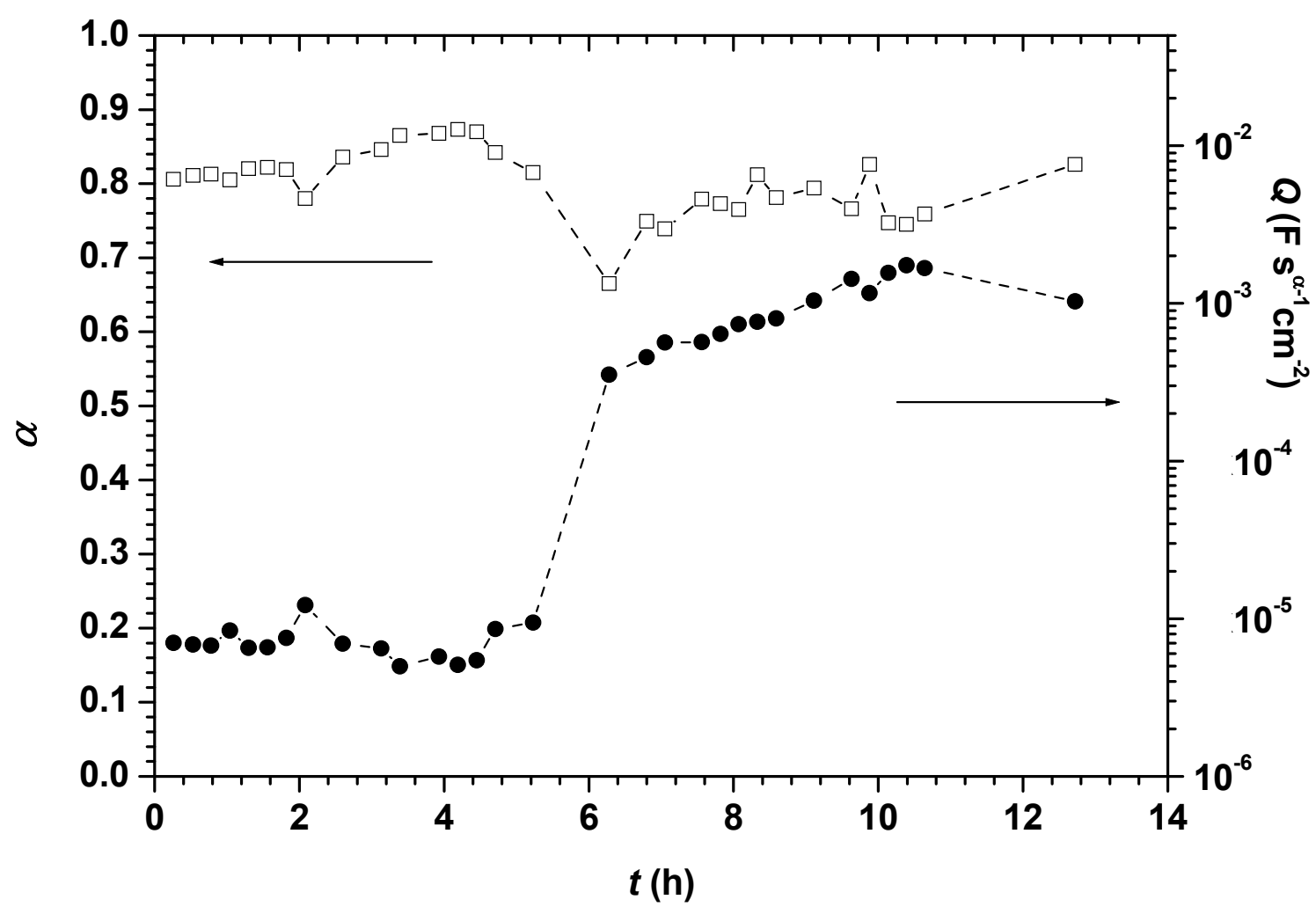

Figure 6 


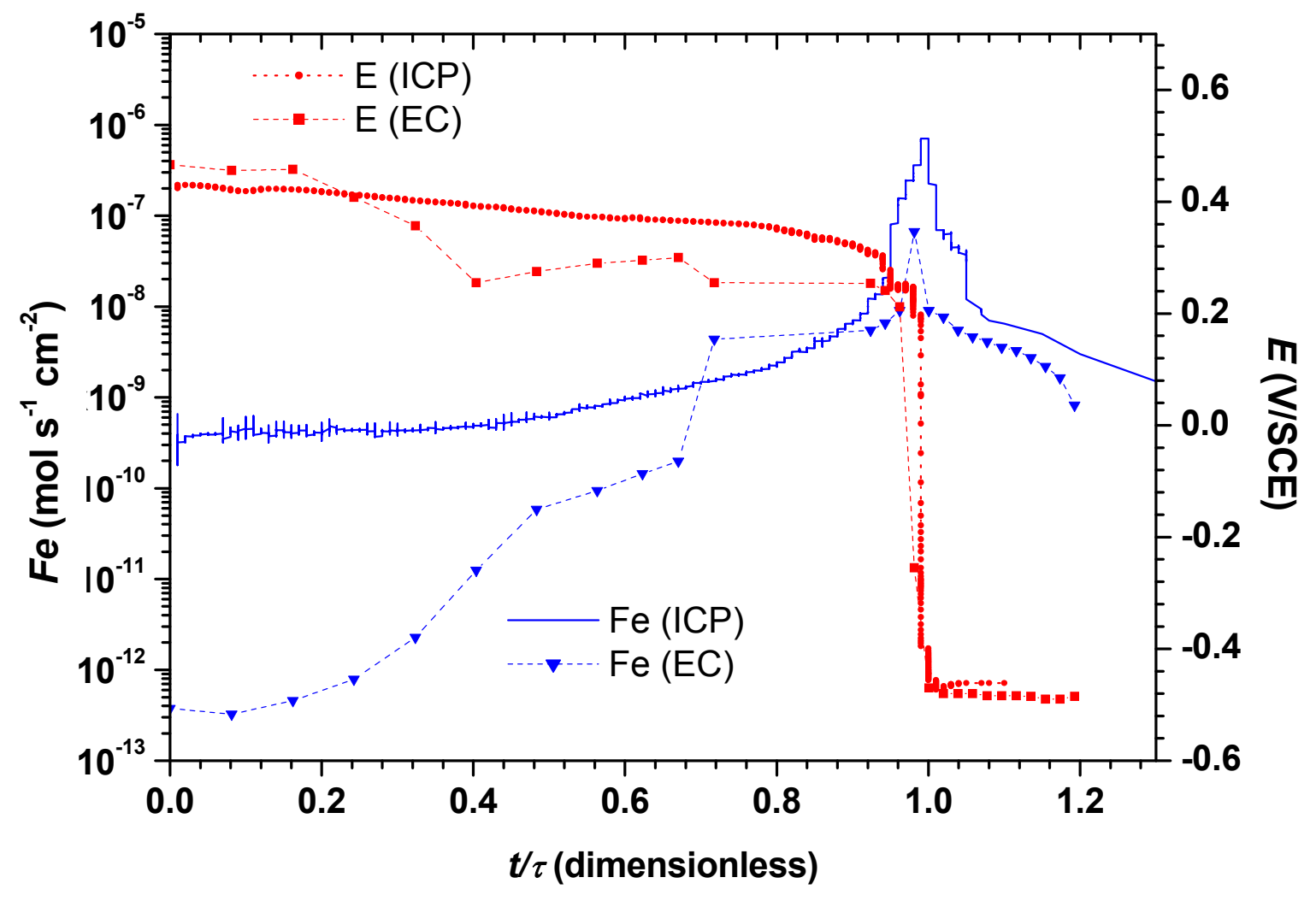

Figure 7 


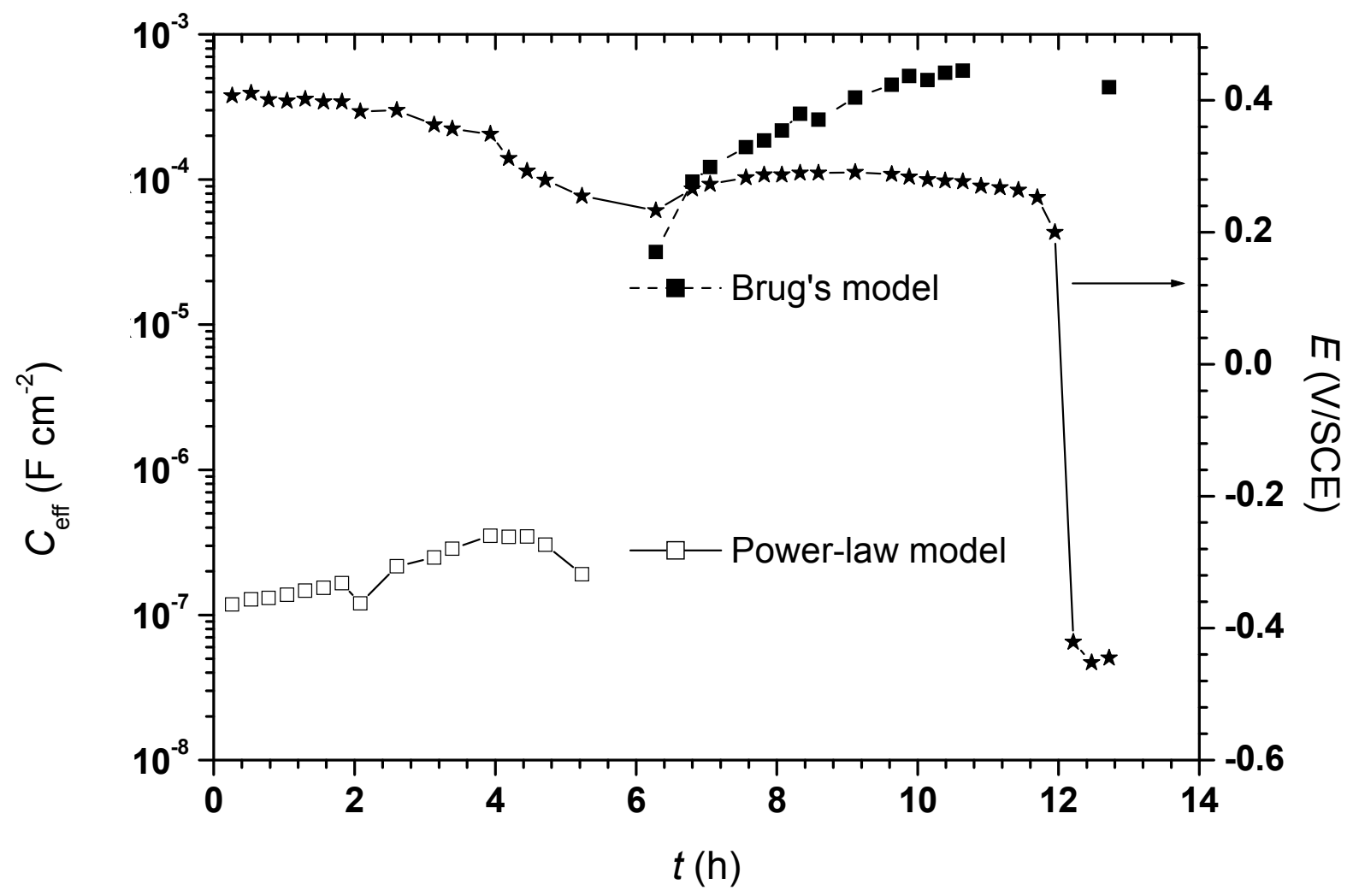

Figure 8 